\title{
Oxygen regime of rivers in the area of sources of economic impact according to long-term monitoring of the Russian meteorological service
}

\author{
A.V. Goncharov ${ }^{1, *}$, V.A. Isaev ${ }^{2}$ and N.M. Yumina ${ }^{1}$ \\ ${ }^{1}$ Department of Land Hydrology, Lomonosov Moscow State University, Moscow, Russia \\ ${ }^{2} \mathrm{OOO}$ "New cloud technologies", Innopolis, Russia
}

\begin{abstract}
The results of long-term observations of the hydrochemical service of the Russian Meteorological Service on the content of dissolved oxygen in the rivers of Russia are considered. Data on the basins of the Amur, Lena, Ob, Volga for 1988-2007 is analyzed. We compared the average monthly oxygen concentrations above and below the sources of exposure - cities, large industrial enterprises - in total, about 100 paired sections were used. The study showed that in about half of these river sections, sometimes (in $14.8 \%$ of cases) small changes in oxygen concentration (6.5-8.3\%) are observed. Wherein, both a decrease and an increase in oxygen concentration can occur below the sources of anthropogenic impact. The latter is typical for winter time, when the flow of heated wastewater into the river leads to formation of an air-hole and the flow of oxygen from the atmosphere into the water. Small rivers in cities experience the greatest stress; however, in general, for all the rivers under consideration, the anthropogenic change in the oxygen regime of the rivers is small and does not significantly affect the sustainability of the development of the territories.
\end{abstract}

\section{Introduction}

The sustainability of development of territories depends not only on the availability of the required volumes of water, but also on its quality, on the state of water bodies. The oxygen regime is an important indicator of the ecological state of rivers, which characterizes the quality of water, the habitat of aquatic organisms, and the trophic status of river ecosystems. The content of oxygen dissolved in water depends on the intensity of atmospheric reaeration of water masses and biological production and destruction processes. Spatio-temporal fluctuations in dissolved oxygen are associated with various geographic and hydrological factors: type of channel processes, geochemical characteristics of landscapes, runoff of allochthonous organic matter and biogenic elements, climate that determines the temperature regime of rivers and duration of the freeze-up period [3]. Many

\footnotetext{
* Corresponding author: mama15333@mail.ru
} 
of these factors can be subjected to anthropogenic impacts, as a result of which the oxygen regime of rivers also changes.

The concentration of oxygen dissolved in water is an indicator that is mandatory in assessing water quality and monitoring water bodies and streams. The references contain information on dissolved oxygen for individual rivers $[4,8,9,11,12]$. The purpose of this paper is to clarify the nature of changes in the oxygen regime of Russian rivers in the area of sources of anthropogenic impact - according to the data of long-term monitoring of the Russian Meteorological Service. Such a study will help to highlight the environmental aspects of the sustainability of large areas development.

\section{Materials and Methods of the Studies}

The paper compared the oxygen concentrations measured above the sources of economic impact with those obtained below such objects (cities, towns, industrial enterprises). We used the data of the Russian Meteorological Service for 1988-2007. Only those posts at which observations were carried out regularly (more than 9 times per year) were considered; usually they were located in the area of large settlements.

Therefore, paired points were considered (see Figure 1). In the Volga basin there were 23 of them (on Vyatka, Zhizdra, Zusha, Oka, Protva, and etc.), in the Ob basin - 19 (on the rivers Berd, Biya, Kadat, Kazym, Kondoma, Ob, Tom, Chulym, and etc.); in the Lena basin - 15 (Aldan, Amga, Vilyui, Vitim, Kirenga, Lena, Tyry); in the Amur basin - 35 (on the rivers Amur, Argun, Bureya, Zeya, Tunguska, Shilka, and etc.).

The oxygen concentration in water was determined by the Winkler method [7]. The values obtained were converted to percent saturation in order to consider the effect of temperature. This makes it possible to reduce the number of factors affecting oxygen due to such a rather understandable phenomenon as the reaeration of water with a change in temperature and to draw attention to the biological processes of oxygen consumption (release), which are very difficult to consider.

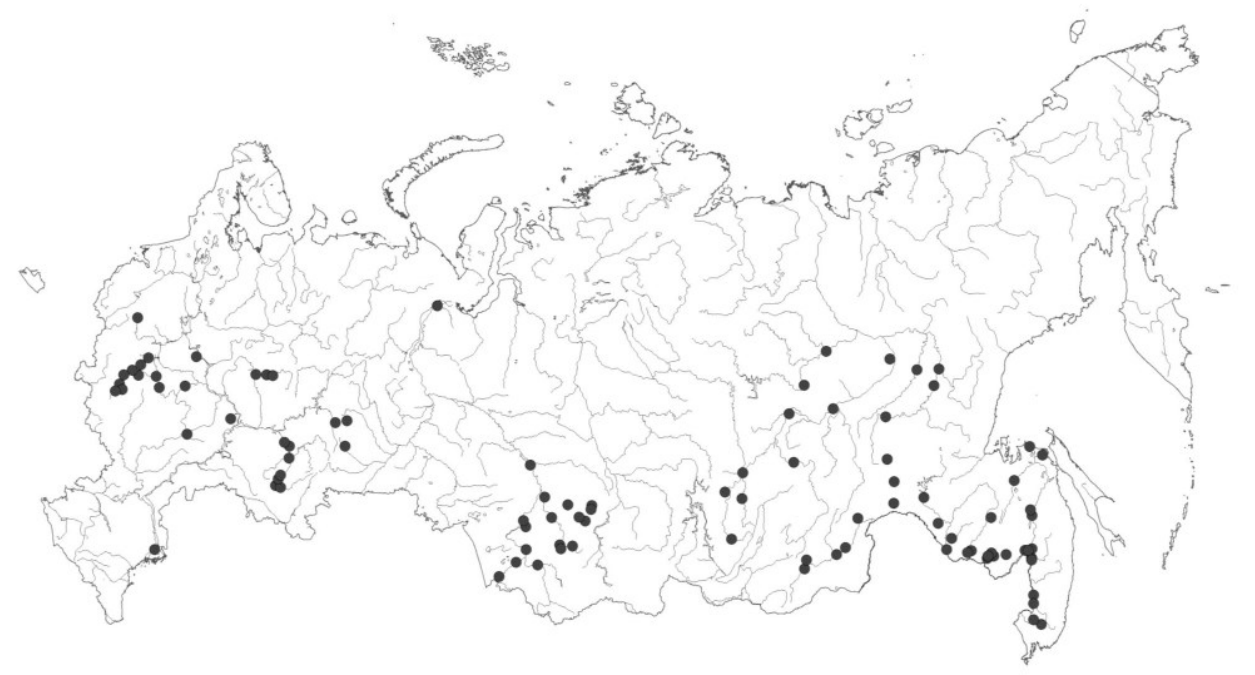

Fig. 1. Location of observation points

The reliability of the difference in oxygen at paired sections was determined by the Mahalonobis distance $[5,10]$, which is used when there is a significant correlation between 
the compared parameters. The Mahalanobis distance $\left(\mathrm{d}_{\mathrm{q}, \mathrm{p}}^{2}\right)$ less than 3.84 indicates the unreliability of oxygen differences above and below the source of exposure).

\section{Study Results and their Discussion}

The results are collected in Table 1; the calculations used average long-term values for each month of the year. It can be seen that in most cases (53 out of 92) there was a significant change in oxygen below the sources of anthropogenic impact.

Table 1. The number of paired posts where there are significant changes in oxygen above and below the source of anthropogenic influence (average long-term values for each month are used).

\begin{tabular}{c|c|c|c|c|c|c|c|c|c|c|c|c}
\hline \multirow{2}{*}{$\begin{array}{c}\text { River } \\
\text { basins }\end{array}$} & $\begin{array}{c}\text { Number of } \\
\text { paired points } \\
\text { experiencing } \\
\text { the influence }\end{array}$ & \multicolumn{10}{c}{ The number of months for which there are significant } & \multicolumn{1}{c}{$\begin{array}{c}\text { Total } \\
\text { paired } \\
\text { points } \\
\text { counted }\end{array}$} \\
\hline & 1 & 2 & 3 & 4 & 5 & 6 & 7 & 8 & 9 & 10 & 23 \\
\hline Volga & $15(65 \%)$ & 9 & 3 & 2 & & & & 1 & & & & 15 \\
\hline Lena & $5(33 \%)$ & 2 & 2 & & & & & & 1 & & & 19 \\
\hline Ob & $16(84 \%)$ & 4 & 3 & 3 & 2 & 1 & 2 & 1 & & & & 19 \\
\hline Amur & $17(49 \%)$ & 4 & 6 & 4 & & & & 1 & & 1 & 1 & 35 \\
\hline Total & $53(100 \%)$ & 19 & 14 & 9 & 2 & 1 & 2 & 3 & 1 & 1 & 1 & 92 \\
\hline
\end{tabular}

However, in each pair of points, changes are rarely observed. As can be seen in Table 1, there is not a single pair of points where changes were recorded for more than 10 months a year. On the contrary, in most cases such changes occur only 1 or 2 months a year. So, examining the Lena basin, it can be seen that there is 1 paired point, where the anthropogenic transformation of the oxygen regime takes place over 8 months; at two points - within 2 months and at one - within only one month.

Of all the compared pairs of monthly mean values, significant differences in oxygen were noted in $14.8 \%$ only. Among them, $6.5 \%$ refers to an increase in oxygen below the source of exposure and $8.3 \%$ - to an increase (Table 2). That is, for the majority of monthly averages $(85.2 \%)$, there are no significant changes.

Table 2. The frequency of a significant decrease or increase in the concentration of dissolved oxygen in rivers below the sources of exposure

\begin{tabular}{c|c|c|c|c|c}
\hline \multirow{2}{*}{$\begin{array}{c}\text { River } \\
\text { basins }\end{array}$} & $\begin{array}{c}\text { Total number } \\
\text { of } \\
\text { observations } \\
\text { (months) }\end{array}$ & $\begin{array}{c}\text { Increased oxygen concentration } \\
\text { observations } \\
\text { (months) }\end{array}$ & $\begin{array}{c}\text { Number of } \\
\text { observations } \\
\text { (\% of the total) }\end{array}$ & $\begin{array}{c}\text { Dumber of } \\
\text { observations } \\
\text { (months) }\end{array}$ & $\begin{array}{c}\text { Number of } \\
\text { observations } \\
\text { (\% of the total) }\end{array}$ \\
\hline Volga & 262 & 10 & 3.8 & 18 & 6.9 \\
\hline Amur & 379 & 21 & 5.5 & 33 & 8.7 \\
\hline Ob & 222 & 30 & 13.5 & 21 & 9.5 \\
\hline Lena & 122 & 4 & 3.3 & 10 & 8.2 \\
\hline On average & & & 6.5 & & 8.3 \\
\hline
\end{tabular}

According to Table 2, a decrease in oxygen content below the source of exposure is noted only slightly more often than an increase. The latter is usually observed in winter - as a result of heat exposure. In this case, the river (or its section) does not freeze and oxygen enters the water from the atmosphere [2]. In summer, an increase in oxygen concentration 
below the source of exposure may occur as a result of photosynthesis enhanced by the discharge of nutrients into the river.

In addition to the characteristics discussed above, the magnitude of the decrease or increase in the oxygen concentration at the lower section as compared to the upper sections is of great importance. The analysis shows that such changes are relatively small: the average decrease is $9.3 \%$, and the increase is $10.4 \%$. Moreover, we are talking about a small array of all average monthly values (about $14.8 \%$ ). For the main part of the paired points (85.2), no significant change in oxygen was found.

Wherein, there are some of them, the oxygen regime of which is undergoing significant anthropogenic transformation. Therefore, further we will consider more detailed information on individual river basins.

In the densely populated Volga basin, changes in oxygen concentration in rivers below the sources of river impact occur in $65 \%$ of the cases considered (Table 1). They are usually episodic and do not last more than 2-3 months a year.

One of the examples of a clear anthropogenic change in the oxygen regime here is the section of Sura river in the area of Penza (Fig. 2), where the differences in the monthly average values of the dissolved oxygen content are reliable for 7 months a year. The average annual decrease in the oxygen content in the lower section as compared to the upper section is $8.5 \%$. The source of pollution is the half-million city of Penza, which has a number of large industrial enterprises. In addition, the Surskoe reservoir is located above the city of Penza, which also affects the oxygen content in the downstream sections of the river.

$$
\mathrm{O}_{2}, \%
$$

(a)

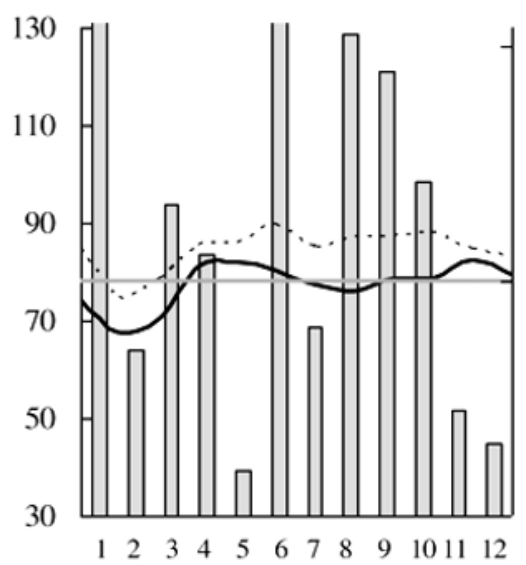

(b)

1

$\mathrm{d}^{2} \mathrm{q}, \mathrm{p}$

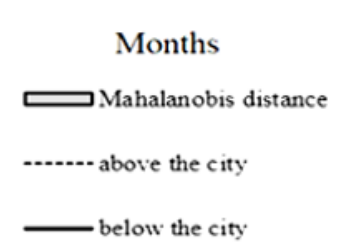

Fig. 2. Oxygen content (\% of saturation) in the Sura River in the area of Penza (A) and in the Oka River above and below the city of Murom (B).

In the Oka River, anthropogenic changes in the oxygen regime are rarely recorded. In some months of the winter low-water period, when the water content and the self-cleaning capacity of the river decrease, significant differences are observed in the sections above and below the cities. A significant decrease in the oxygen content was found in the water of the 
Oka River below the city of Murom in February and November (Fig. 2), in the city of Ryazan - in May. The opposite situation - an increase in the oxygen content in river waters, is observed in the sections below Orel — in January, Kaluga — in February, which is explained by atmospheric aeration of water in the river sections not covered with ice arising from the warming effect of urban wastewater.

In the Lena basin, a small population and industrial enterprises have almost no effect on the oxygen regime of rivers: it is absent in $67 \%$ of the cases considered (Table 1). Exception is the city of Yakutsk, whose effluents reduce the content of dissolved oxygen in the Lena river for 8 months a year. However, this decline is not large and averages $5 \%$ per year.

In the $\mathrm{Ob}$ basin, more often than in other regions, there are changes in the oxygen regime of rivers passing through cities (Tables 1,2). A significant effect on the oxygen regime of watercourses at various points here can last from 1 to 7 months. Wherein, in the $\mathrm{Ob}$ basin, cases of an increase in the oxygen content below cities are more often detected than its decrease (13.5\% versus $9.5 \%$ - see Table 2$)$. An increase is observed, as a rule, in winter, when, due to the influx of warm waters, ice cover does not form on the river and active atmospheric aeration of water occurs (the Ob river in Novosibirsk, the Chulym river in Nazarovo, the Tom river in Kemerovo).

In the $\mathrm{Ob}$ river downstream the Novosibirsk hydroelectric power station in winter the air-hole forms, which in different years has a length of 10 to $30 \mathrm{~km} \mathrm{[6].} \mathrm{Therefore,} \mathrm{during}$ the freeze-up period, water saturation with oxygen, when the river passes through the city, significantly increases due to aeration in the open section of the channel (Fig. 3). In the warm season, the differences in the oxygen content downstream the hydroelectric power station are leveled.

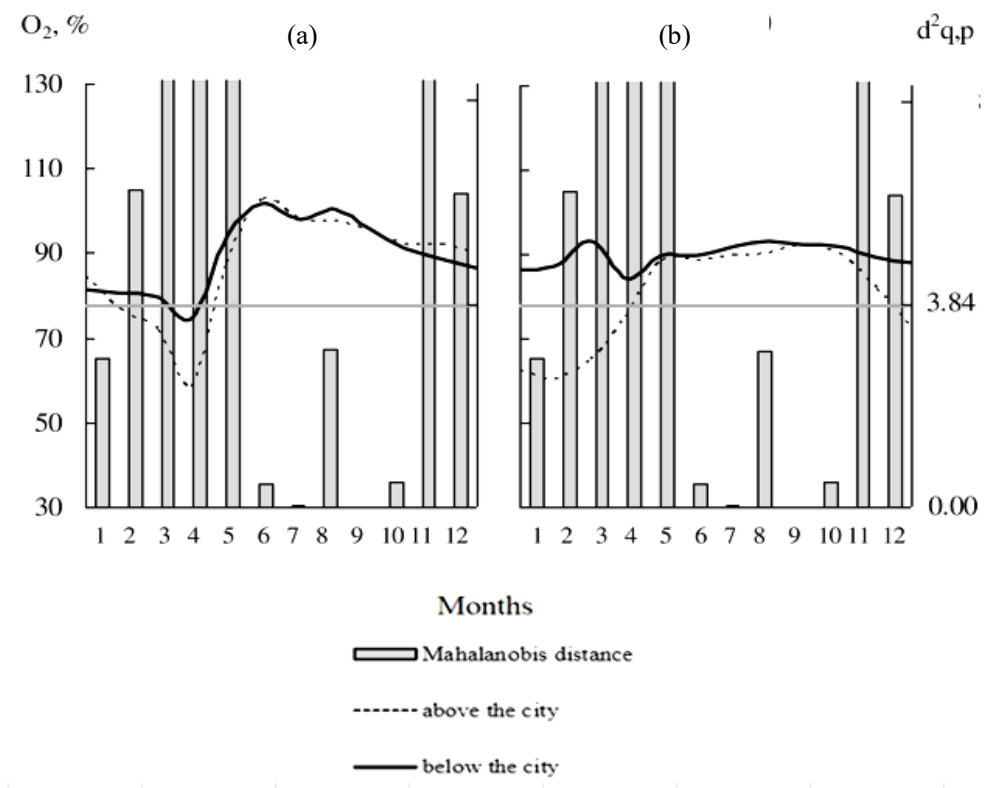

Fig. 3. The degree of water saturation with dissolved oxygen in the Ob river near Novosibirsk (A) and in the Chulym River near Nazarovo (B).

The state regional power plant located in Nazarovo has a powerful warming effect on the Chulym River. As a result, the river does not freeze in winter and atmospheric aeration leads to an increase in the oxygen content below the state regional power plant by $25 \%$ compared to the upstream section of the river (Fig. 3). 
In the $\mathrm{Ob}$ basin, there are small rivers, the oxygen regime of which has significantly changed: in the city of Tomsk it is the Ushayka River, in the city of Novosibirsk - the Tula River and the Kamenka River. In the latter, the usual saturation of water with oxygen at the level of $27-45 \%$; an increase (up to $67 \%$ ) occurs only during periods of increased water availability (floods).

Table 1 shows that the largest number of paired points (within the considered data set) is located in the Amur basin. At $51 \%$ of the points, there are no reliable changes in oxygen in the rivers. Wherein, there are rivers in the Amur basin, the oxygen regime of which is most strongly transformed: on the Spasovka River near Spassk-Dalny, a significant decrease in oxygen is observed for 10 months a year, on the Arsenyevka River near the city of Arseniev - within 9 months (Fig. 4). Within floods (in April, November), the oxygen content increases as a result of dilution of pollution and increased aeration.

$$
\mathrm{O}_{2}, \%
$$

(a)

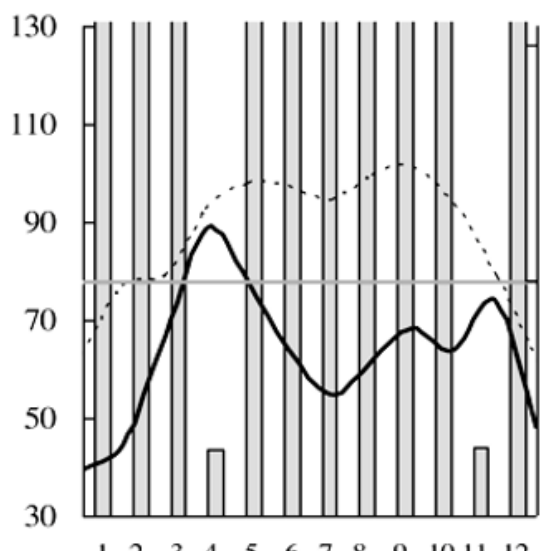

(b)

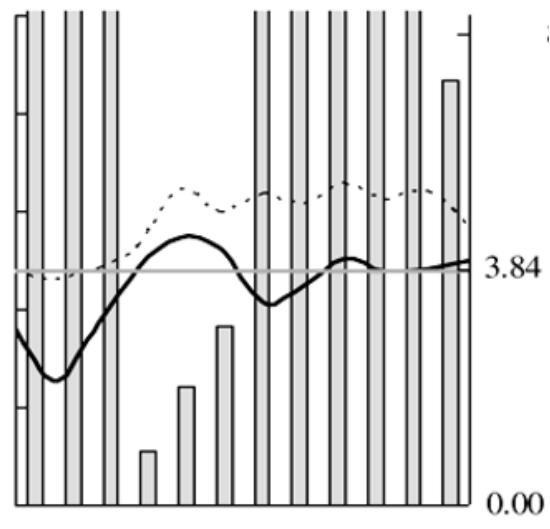

$\begin{array}{lllllllllllll}1 & 2 & 3 & 4 & 5 & 6 & 7 & 8 & 9 & 10 & 11 & 12\end{array}$ $d^{2} q, p$

\section{Months}

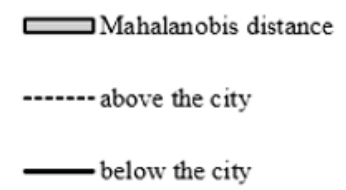

Fig. 4. The degree of saturation of water with dissolved oxygen in the Spasovka River near the city of Spassk-Dalny (A) and in the Arsenyevka River near the city of Arseniev (B).

\section{Conclusions}

1. Almost half of the considered observation points in the Ob, Volga, Lena and Amur basins are characterized by statistically significant changes in the content of dissolved oxygen below the sources of influence.

2. Wherein, such changes are rarely observed - mainly $1-2$ months a year and never occur all year round. They are recorded on average for only $14.8 \%$ of all monthly averages; wherein, in $6.5 \%$ of cases, there is an increase and in $8.3 \%$ - a decrease in oxygen below the source of exposure.

3. Cases of an increase in dissolved oxygen are mainly related to the winter period. The reason is the influx of warm water, which prevents the establishment of ice, as a result of which there is an active supply of oxygen from the atmosphere. 
4. Small rivers of large settlements are most susceptible to anthropogenic transformation of their oxygen regime.

5. The results obtained indicate that, in general, anthropogenic changes in the oxygen regime are not a factor that can have a significant impact on the sustainability of development of Russian territories.

\section{Acknowledgments}

The article was prepared as research work of the Department of Land Hydrology, Faculty of Geography, Moscow State University (Topic No. 121051400038-1).

\section{References}

1. A.V. Goncharov, M.B. Zaslavskaya, V.A. Isaev, E.E. Lobchenko, I.P. Nichiporova, Geography and natural resources, 3, 69-76 (2013)

2. A.V. Goncharov, V.A. Isaev, E.E. Lobchenko, I.P. Nichiporova, Proceedings of the III All-Russian conference "Ice and Thermal Processes on Water Bodies of Russia", Onega, Arkhangelsk region, Russia, June 6-11, 2011, Institute of Water Problems, RAS, 286-290 (2011)

3. A.V. Goncharov, V.A. Isaev, E.E. Lobchenko, I.P. Nichiporova, Water Resources, 38(5), 564-570 (2011)

4. A.V. Goncharov, E.E. Lobchenko, I.P. Nichiporova, Proceedings of the scientific conference "Modern problems of hydrochemistry and the formation of water quality", Rostov-on-Don, 97-99 (2010)

5. A.A. Isaev, Statistics in meteorology and climatology, 248 (1988)

6. D.V. Kozlov, Fundamentals of Hydrophysics. Tutorial, 246 (2004)

7. RD 52.24.419-2005, Mass concentration of dissolved oxygen in waters. Methods for performing measurements by the iodometric method, 22 (2005)

8. M.A. Sokolova, V.E. Topnikov, Biol. int. water, 97, 61-66 (1994)

9. L.M. Sorokovikova, Gas regime of the Yenisei in modern conditions, Water resources, 24(1), 86-89 (1997)

10. A.V. Khristoforov, Reliability of river flow calculations, 168 (1993)

11. M. Boeder, H. Chang, Journal of Environmental Management, 87(4), 567-581 (2008)

12. P. Chambers, J. Culp, N. Glozier, K. Cash, F. Wrona, L. Noton, Environmental Monitoring and Assessment, 113, 117-141 (2006) 